\title{
REFERENCE THEORIES AND THE RELEVANCE OF DESCRIPTIONS
}

\author{
LUIS FERNÁNDEZ MORENO \\ https:/ / orcid.org/0000-0002-3940-0998 \\ Complutense University of Madrid \\ Department of Philosophy \\ Madrid \\ Spain \\ luisfm@ucm.es
}

\begin{abstract}
Article info
CDD: 401

\section{Keywords}

Reference

Reference-fixing

Natural kind noun

Proper name

Description
\end{abstract}

Received: 27.05.2020; Revised: 06.08.2020; Accepted: 15.08.2020

https://doi.org/10.1590/0100-6045.2020.V43N4.LM

\begin{abstract}
Mario Gómez-Torrente (2019) is a fundamental contribution to the issue of reference and especially of reference fixing. In this article I will focus on some questions addressed in it, especially on the relationships between some components of Kripke's, Putnam's and Gómez-Torrente's theories of reference fixing as well as on the relevance of descriptions for those theories; I will then make some observations about Gómez-Torrente's view of the reference-fixing conventions.
\end{abstract}

It is, notwithstanding, appropriate to begin by making some preliminary remarks. Among the questions on the reference of expressions, the most important one concerns the nature of the reference mechanism, i.e., by virtue of what (uses of) expressions become connected (i.e., refer) to certain entities or, as we usually say, how the reference of (uses of) 
expressions is determined. In a theory of reference a distinction is usually made between a theory of the introduction of a term, which explains how the reference (referent) of the term is determined by the speaker(s) who introduced it, and a theory of reference transmission, which explains how the reference of the term is determined for the rest of the speakers. In (2019) the expression 'reference fixing' is used in the sense of reference determination. In this article I will take into consideration natural kind nouns and proper names, given the important similarities between both sorts of expressions, and I will use indistinctly the expressions 'natural kind noun' and 'natural kind term'.

In (2019) the author sometimes implies that he assimilates Kripke's theory of natural kind nouns to that of Putnam's; thus, he speaks on occasions of the 'KripkePutnam picture' (ibid, pp. 14, 154, 181 and 217) and more often of the 'Kripke-Putnam orthodoxy' (in inverted commas) (see e.g. the titles of the first two sections of chapter five as well as pp. 141, 146, 147, etc.). However, he asserts: 'As we will mention in brief notes and asides here and there, Kripke's ideas are different from Putnam's' (2019, p. 141). Indeed, there are some similarities but many differences between Kripke's and Putnam's theories of reference (fixing), some of the latter not being mentioned in (2019), ${ }^{1}$ as a result of which the 'Kripke-Putnam picture' or the 'Kripke-Putnam orthodoxy' should not be spoken of, even in inverted commas, and in such denominations by Putnam's theory it is understood to be the one proposed

${ }^{1}$ I will leave aside some of the differences between Putnam's and Kripke's views which are hardly relevant for Gómez-Torrente (2019), like their discrepant positions on possible worlds and thus on necessity (see, e.g., Putnam 2015, p. 79). 
mainly in the seventies of the last century, especially in (1975b). ${ }^{2}$

An important difference between Putnam's and Kripke's reference theories is the role of experts in the former. They are the speakers of our community who are more knowledgeable than the average speaker concerning the membership conditions into a natural kind and hence on the extension (reference) of the corresponding natural kind term. Since Putnam assumes that the average or typical speakers are willing to defer to experts the reference fixing of natural kind terms as typical speakers use them, an entity falls into the extension of a natural kind term used by the average speaker if it falls into its extension as used by experts. I suppose that Gómez-Torrente would claim that the distinction between expert and non-expert speakers in Putnam's sense is not relevant regarding the reference fixing of nouns for familiar ordinary natural kinds, like 'water', since 'nearly every speaker has hands-on-experience with water' (2019, p. 145). But I presume he will hold that the said distinction is not significant either with respect to the reference fixing of nouns for not so familiar kinds, such as 'sulfur', since in this case Gómez-Torrente alleges that for most typical speakers its reference is fixed by their membership into a chain of transmission or causal chain - in the following I will use both notions interchangeably whose first link is (its uses by) individuals with hands-on experience with sulfur, including the first people who began to use the term "sulfur" (or some ancestor or translation) for the newly discovered [...] substance' (ibid). However, the distinction between more and less familiar natural kinds is

2 The references to Putnam's writings from that period in GómezTorrente (2019) also include Putnam (1973), but the content of this paper is identical, except for footnote 2, with a part of Putnam (1975b). 
imprecise, and it is also the distinction between ordinary and non-ordinary natural kinds - the nouns for the former being the natural kind nouns the author focuses on -, although there are paradigmatic examples of the kinds and the respective terms involved in the last distinction.

It is noteworthy that Kripke does not accept the role played by the notion of expert in Putnam's theory; for Kripke, the only expert(s) regarding a proper name or natural kind term are the speaker(s) who introduced the term in an initial baptism (see Kripke 1986). ${ }^{3}$ Gómez-Torrente's view is more comprehensive, since he includes among the first link(s) of a chain of transmission not only the (first) introducers of a term but also other 'individuals with handson experience' with the referent of a term, and (at least some of) those individuals will be experts in Putnam's sense. Thus, Putnam's recourse to the notion of expert, applied to natural kind terms and to proper names - see (1975b) and (1975c) , conflicts with Kripke's perspective, but is not at odds with Gómez-Torrente's vision to the same extent.

Another difference between Putnam's and Kripke's views concerns the reference transmission of terms. According to Kripke, after a proper name has been introduced in an initial baptism, the name is transmitted to the members of the linguistic community not involved in its introduction (the so-called borrowers) through a chain of transmission, where the links of the chain are those members or rather the uses they make of the name. The reference of a proper name as used by speakers, with the exception of the speaker(s) present at the initial baptism, is fixed by their membership into the chain of transmission concerning the name irrespective of the properties or descriptions they associate with the name.

${ }^{3}$ Kripke's reference theory for natural kind terms is essentially an extension of his theory on proper names.

Manuscrito - Rev. Int. Fil. Campinas, v. 43, n. 4, pp. 74-85, Oct.-Dec. 2020. 
It is worth mentioning that in (1973) Putnam proposed a theory of reference fixing according to which magnitude terms and in general natural kind terms are introduced by descriptions, which are required to be approximately correct or true. In a similar sense he asserts that for someone to refer to an individual by a name it is required that he or she would have some true or approximately true beliefs about the individual referred to:

I do not feel that one should be quite as liberal as Kripke is with respect to the causal chains one allows. [...]; unless one has some beliefs about the bearer of the name that are true or approximately true, then it is at best idle to consider that the name refers to that bearer in one's idiolect. (Putnam 1973, p. 203).

Therefore, according to Putnam, some of the descriptions or properties that users of a term and hence also borrowers associate with it must be true or approximately true of its referent, since otherwise they would lack any justification to consider that by means of the term they are referring to such an entity. Thus, Putnam, unlike Kripke, supports the necessity of descriptive requirements on the reference transmission of a term. In this regard it is noteworthy that Gómez-Torrente includes some descriptive elements in the conventions for successful proper name and natural kind noun transmission. On the one hand, in the first convention 'an object o' (2019, p. 96) is resorted to; although in order to avoid humans being considered as 'objects', perhaps it would be more appropriate to speak in that convention of 'individual entity'. On the other hand, in the second convention it is asserted that ' $\mathrm{N}$ refers to a certain substance (/species/phenomenon)' (ibid, p. 162) and that ' $\mathrm{N}$ is used as a noun for a natural kind' (ibid). On this matter we could ask Gómez-Torrente for a characterization of natural 
kinds applicable to both, scientific kinds and ordinary natural kinds - in (2019) he mainly deals with their differences - as well as for more precision in his assertion that 'on the view I am inclined to adopt, ordinary kinds are sui generis universals' (2019, p. 178, n. 25). In any case, the descriptive elements contained in the said conventions are minimal, and I assume that Gómez-Torrente would claim that the recourse to more specific descriptive elements would be liable to the arguments of the ignorance/error type.

However, one of the most important questions I would pose regarding Gómez-Torrente (2019) concerns his view on the successful introduction of natural kind nouns and proper names. A similarity between Kripke's and Putnam's theories is that both authors maintain that proper names and ordinary natural kind nouns are not synonymous with descriptions that normal competent speakers usually associate with them and that would determine their reference - in what is today a common denomination, those terms are nondescriptional - and most authors, including GómezTorrente, agree with that view. However, the question is whether there are any descriptive requirements on the introduction of said terms.

Kripke asserts that the introduction of proper names (and natural kind nouns) takes place in an initial baptism, which proceeds 'by ostension [...] or [...] by a description' (1980, p. 96), and he also asserts that an initial baptism 'is explained in terms either of fixing a reference by a description, or ostension (if ostension is not to be subsumed under the other category)' (Kripke 1980, p. 97; emphasis added). In my view the ostensive introduction of a term should be subsumed under the descriptive one. Since the ostension by itself is ambiguous the act of pointing to an individual accompanied by the use of a demonstrative has to be supplemented by 
means of a general term like a sortal term, rendering a demonstrative description. ${ }^{4}$

Furthermore, although it is not generally accepted as being Kripke's view, I would claim that Kripke concedes that the description theory is usually adequate as a theory for the introduction of proper names. He asserts that there is a sort of cases in which the description theory is true, the cases of that type being 'usually initial baptisms' (Kripke 1980, p. 78; see also ibid, p. 59, n. 22), although Kripke points out that the use of names in initial baptisms is 'only [...] a rare class of cases' in the use of names (ibid, p. 78). This qualification is obvious since most uses of names are not the ones involved in their introduction.

The question to be put forward is whether the description or sortal term used in the introduction of a term has to be true or at least approximately true of the object referred to. In my opinion, some of Kripke's assertions point to the view that, even though the description by means of which the reference of a name has been fixed may not be true of the referred object, it has to be approximately true. Alluding to Donnellan's view concerning descriptions used referentially which may be false of the object identified by them, Kripke asserts:

"In such cases, the description which fixes the reference clearly [...] [does not] hold of the object, though a more cautious substitute may be. If such cautious substitute is available, it is really the substitute which fixes the reference."(Kripke 1980, p. 80, n. 34; emphasis added).

\footnotetext{
${ }^{4}$ By a "sortal term" I understand sortal terms in the broad sense, that is, general terms that provide criteria for identity concerning the entities to which they apply; thus count terms and mass terms are sortal terms.
} 
However, a description or a sortal term that constitutes a more cautious substitute for another cannot be very different from it; e.g., the use of the sortal term 'planet' instead of the term 'star' in the case of the description that introduces the name 'Phosphorus' (ibid). Therefore, Kripke's view seems to be that a proper name or natural kind noun is introduced in an initial baptism in which its reference is fixed; that baptism can be considered to take place through a description, and thus by means of the sortal term contained in it, and that description has to be true or, at least, approximately true of the baptized (i.e., referred) object. ${ }^{5}$ Something similar happens in the case of Putnam's theory in (1975b); he asserts that there are two procedures to introduce the reference of a natural kind term, like 'water', in the idiolect of a speaker procedures, similar to those mentioned by Kripke regarding initial baptisms -, to wit, an 'ostensive definition' or demonstrative description, which contains implicitly or explicitly a sortal term, and a (definite) description which Putnam denominates 'operational definition', and as already mentioned, those descriptions have to be in Putnam's view true or approximately true.

However, if one accepts that there are descriptions involved in the successful introduction of proper names and

5 In Devitt/Sterelny (1999) it is alleged that some sortal terms/descriptions are required in the introduction of proper names so as to solve the qua-problem for proper names (1999, pp. 79 ff.; see note 7) and the two parts of the qua-problem for natural kind terms (1999, pp. 90 ff.). See on this matter Fernández Moreno (2006, pp. 265 ff.). Regarding natural kind nouns Gómez-Torrente just takes into consideration as qua-problem the second part of the last problem (see Gómez-Torrente 2019, pp. 148 ff.), since this is the only one relevant to the objection against Kripke's and Putnam's views resulting from the fact that the members of a natural kind are at the same time members of natural kinds of different levels. 
natural kind nouns which have to be true or approximately true of their referent, the reference of those terms will have some indeterminacy, due to the indeterminacy of the expression 'approximately true'. The view that terms have referential indeterminacy is also held by Gómez-Torrente, who explains it mainly alleging that the reference-fixing conventions that he postulates only provide roughly sufficient conditions for reference (and reference failure).

Gómez-Torrente asserts that his theory is of Kripkean inspiration (see, e.g. ibid, p. VIII) and he proposes referencefixing conventions for the successful (implicit or explicit) introductions of proper names and of natural kind nouns; he asserts that the introductions in question are of two sorts, i.e., 'via perceptual intention' and "via description" (2019, pp. 93 and 95 as well as 160-161). I wonder whether they, or at least the successful explicit introductions (however see note 7), could be reformulated in such a way that they were both cases of introductions via description, in the first case paradigmatically by means of demonstrative descriptions and in the second case through demonstrative or definite descriptions, ${ }^{6}$ and conceding an affirmative answer to that question $^{7}$ descriptions would have more relevance for

6 Gómez-Torrente asserts that the two types of explicit introduction regarding proper names "cover the basic Kripkean cases of 'initial baptism' by means of explicit dubbings via demonstration and description" (2019: 93). See the above considerations on the ostensive introduction, i.e., via demonstration as a sort of descriptive introduction.

7 In the conventions for successful (explicit or implicit) name introduction via perceptual intention it is alluded to the object that the introducer 'is clearly perceiving' (2019, p. 93 and 95), but here arises the qua problem for proper names (see Devitt/Sterelny 1999, pp. 79 ff., and pp. 90 ff.) - a similar assertion applies to the successful (explicit or implicit) natural kind noun introduction via perception (2019, pp. 160-161), but I concentrate on proper 
reference fixing theories than Gómez-Torrente is willing to concede, since the successful introductions of proper names and natural kind terms would be via descriptions. And one could add the qualification that those descriptions have to be, if not true, approximately true of the object or samples referred to. It remains to be known what Gómez-Torrente's answer would be.

At the basis of Gómez-Torrente's view of reference fixing in (2019) are the reference-fixing conventions underlying (the use of) different sorts of expressions, like proper names and natural kind nouns, which account for some phenomena and intuitions concerning these expressions. I would like to make two considerations on that sort of conventions. The author asserts, e.g., that they are 'somehow knowable' (ibid, p. 82) by normal competent speakers, or that these speakers have some kind of familiarity' (ibid, p. 12) with them or 'are familiar with [...] [them], in some appropriately weak sense' (ibid., p. 160). I wonder if those assertions could be made more precise. In this regard, I would make three considerations. Firstly, the fact that those conventions render only imprecise reference conditions does not seem to justify that the speakers'

names. That problem and the proposal for sorting it out can be put forward as follows. In the introduction of a proper name for an object we only perceive a space-temporal fragment of it, but in order that the name be introduced for the object qua whole object it is required that the introducer of the name conceptualize (implicitly or explicitly) the object by means of some sortal term, in such a way that if the introducer were very wrong about the application of the term to the object, the name would lack reference. Thus, the so-called successful introductions via perceptual intention can be regarded as introductions via demonstrative descriptions, formed with the required sortal term, and the two provisos included in the said convention do not solve the abovementioned problem in the case of this being the first introduction of the name. 
knowledge of them should also bear such sort of imprecision. Secondly, I would concede that the said conventions are not completely known by normal competent speakers because, among other reasons, they contain a theoretical apparatus not known by them. Thirdly, Gómez-Torrente alleges that the observance of those conventions is manifested in the linguistic behavior of normal competent speakers (see, e.g., pp. 160 and 197, n. 24), which could support the view that the said conventions are at least 'somehow knowable' by them. In one case he gives an example of such behavior; thus, regarding proper names 'the relevant kind of behavior might simply involve the acceptance or denial that particular objects are being talked about with specific uses of names' (ibid, p. 90), and a similar example would be applicable to natural kind terms. My question is whether Gómez-Torrente would consider the possibility of resorting to the procedures of experimental semantics to back up his claims about the 'somehow knowable' conventions and their manifestations in linguistic behavior.

\section{REFERENCES}

DEVITT, M. and K. STERELNY. Language and Reality. An Introduction to the Philosophy of Language. Cambridge, Mass.: MIT Press, 1999, 2nd revised and enlarged edition; 1st edition, 1987.

FERNÁNDEZ MORENO, L. The Reference of Natural Kind Terms. Frankurt am Main: Peter Lang, 2016.

GÓMEZ-TORRENTE, M. Roads to Reference: An Essay on Reference Fixing in Natural Language. Oxford: Oxford University Press, 2019. 
KRIPKE, S. Naming and Necessity. Oxford: Blackwell, 1980. (Revised and enlarged edition, first published in D. Davidson and G. Harman (eds.), Semantics of Natural Language. Dordrecht: Reidel, 1972).

KRIPKE, S. "A problem in the theory of reference: the linguistic division of labor and the social character of naming". In V. Cauchy (ed.), Philosophy and Culture. Proceedings of the XVIIth World Congress of Philosophy. Montreal: Editions de Beffroi, pp. 241-247, 1986.

PUTNAM, H. "Meaning and reference". The Journal of Philosophy, LXX, pp. 699-711, 1973.

PUTNAM, H. Mind, Language and Reality. (Philosophical Papers, Vol. 2). Cambridge: Cambridge University Press, 1975a.

PUTNAM, H. "Explanation and reference" (originally published in 1973), using the reprinted edition in $\mathrm{H}$. Putnam 1975a, pp. 196-214.

PUTNAM, H. "The meaning of 'meaning"'. In H. Putnam 1975a, pp. 215-271. (Quoted as 1975b).

PUTNAM, H. "Language and reality". In H. Putnam 1975a, pp. 272-290. (Quoted as 1975c).

PUTNAM, H. "Intellectual autobiography of Hilary Putnam”. In R.E. Auxier et al. (eds.), The Philosophy of Hilary Putnam. Chicago, Ill.: Open Court, pp. 1-110, 2015.

$(c))$ EY 